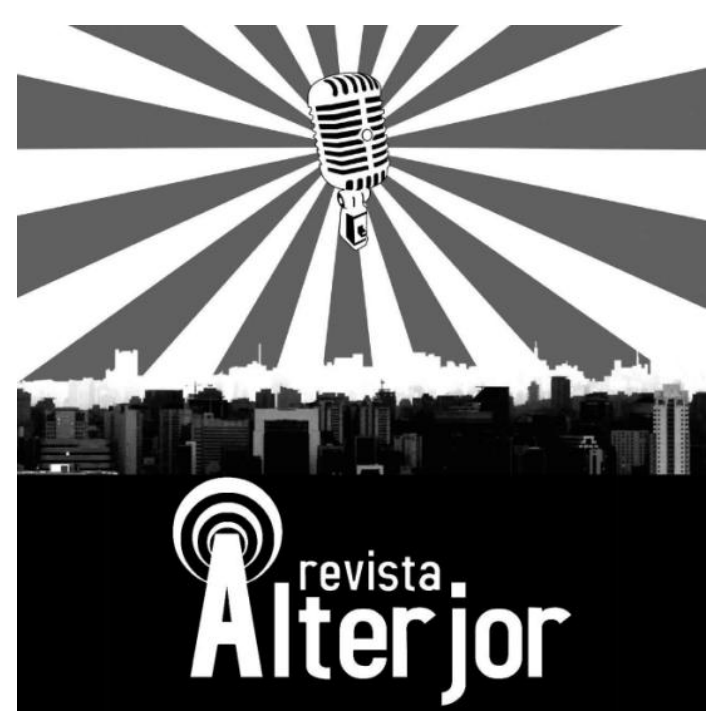

\title{
PROGRAMAÇÃO RADIOFÔNICA E INFÂNCIA: TEMÁTICA, ESTILO \\ E FORMA COMPOSICIONAL DE PROGRAMAS INFORMATIVOS VOLTADOS PARA O PÚBLICO INFANTIL ${ }^{1}$
}

\author{
Michele Letícia Custódio ${ }^{2}$ \\ Suely Maciel ${ }^{3}$
}

RESUMO: O estudo discute a temática, o estilo e a forma composicional de programas destinados ao público infantil e debate a importância de produções em mídia sonora voltadas para o segmento. A partir da análise de temas, seções, estilos de locução, propostas editoriais etc. dos programas Unespinha e Mambembeiro, o estudo discute a repetição, nas atrações, de algumas fórmulas próprias da produção de conteúdos para o público adulto e a pouco criativa e diversificada exploração da sintaxe radiofônica, o que acarreta baixo estímulo à imaginação do ouvinte criança e se soma ao emprego de estratégias que mimetizam o discurso infantil.

PALAVRAS-CHAVE: Rádio infantil. Programação Radiofônica; Jornalismo; Unespinha; Mambembeiro.

ABSTRACT: The following article pursues to understand the theme, structure and compositional form of journalistic radio programs aimed at childhood and discusses the importance of sound media productions for the segment. From the analysis of sections, themes, speaker strategies, editorial proposals and others, the study corroborates the evaluation that the majority of programs aimed at children and teenagers are not very inventive and poor in stimulating the listener's imagination, given the little variety of formats presented, the restricted exploitation of radio language resources and the use of childish strategies on the discussion of subjects.

KEYWORDS: Child radio. Radio programming. Journalism. Unespinha. Mambembeiro.

\footnotetext{
${ }^{1}$ Pesquisa financiada pelo Conselho Nacional de Desenvolvimento Científico e Tecnológico (CNPq).

Bacharel em Comunicação Social Jornalismo, pela Universidade Estadual Paulista (Unesp). Contato: michele.custodio@unesp.br

3 Pós-doutorado em Comunicação pela Universidade Autônoma de Barcelona (UAB); docente do Programa de PósGraduação em Mìdia e Tecnologia (PPGMiT), da Universidade Estadual Paulista (Unesp). Contato: suely.maciel@unesp.br
}

\section{Revista ALTERJOR}

Grupo de Estudos Alterjor:Jornalismo Popular e Alternativo (ECA-USP)

Ano 10 Volume 02 Edição $22 \quad$ Julho-Dezembro de 2020

Avenida Professor Lúcio Martins Rodriģues, 443, Cidade Universitária, São Paulo, CEP: 05508-020 


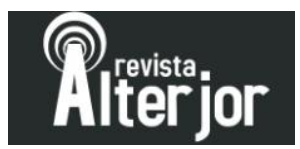

\section{Introdução}

Meio de comunicação fundamental desde a década de 1920, o rádio é uma mídia dinâmica, capaz de se adequar às novas tecnologias, às diferentes demandas de público e de aprimorar suas técnicas e estilos, conforme os recursos de cada época (Ferraretto, 2014). Exemplos dessa capacidade de se metamorfosear e se adaptar são a transmissão via satélite, a passagem do sistema AM para o FM e, na atualidade, a exploração crescente das plataformas on-line e da programação on demand, em que apostas tradicionais de produção passam por reformulações devido às implicações da convergência digital dos últimos anos (Herschmann; Kischinhevisky, 2008, p. 104)

Essa capacidade de se reinventar constantemente permite ao rádio fazer frente aos desafios por novos formatos e conteúdos e, consequentemente, também contemplar diferentes gostos e demandas da audiência, sempre se adaptando às novas tecnologias. Isso, porém, não tem sido suficiente para garantir uma programação que atenda amplamente a todos os públicos, como, por exemplo, o de crianças e pré-adolescentes, o qual se depara, desde sempre, com escassa oferta de produções adequadas, atraentes e relevantes.

Tal cenário sustenta-se no descrédito das emissoras quanto ao retorno publicitário ou a uma audiência significativa (Haussen, 1988). Além disso, as grades de programação consolidadas e engessadas, a preocupação com retorno publicitário e a 'acomodação' de propostas e audiência deixam pouco espaço para a experimentação e a aposta em auditórios diferenciados. Reside aí, porém, um equívoco, pois, segundo pesquisa realizada com crianças de seis a 11 anos, das classes A, B e C, cerca de $87 \%$ delas ouvem rádio regularmente e $49,1 \%$ escolhem pessoalmente o que vão ouvir (Cavalcante; Lima, 2006, p. 42). Dessa maneira, ao não considerar o público infantil, as emissoras não apenas estão perdendo os ouvintes de agora, mas também não contribuem para a formação e fidelização de uma audiência futura.

Diante da restrita oferta de produções dirigidas especificamente a ele, esse grande contingente de ouvintes mirins acaba consumindo maciçamente programação feita para adultos, principalmente o entretenimento musical, nas rádios comerciais 


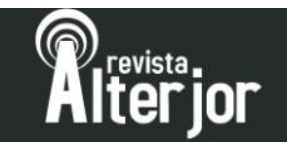

(Fernandes, 2016). Projetos diferenciados concentram-se basicamente em emissoras públicas/educativas e na internet, mas também são pouco conhecidos (Ribeiro, 2016). Tais propostas se estendem da mera programação musical à contação de histórias, à discussão da realidade sociocultural e à divulgação científica e tecnológica.

Entre os programas infantis cujo carro-chefe é a articulação entre informação, arte e educação, podem ser citados o Mambembeiro e o Unespinha.

Seguindo os passos do extinto Rádio Maluca ${ }^{4}$ e simulando a linguagem circense e de picadeiro, o Mambembeiro apresenta-se como um programa informativo e um “espetáculo para ouvir e imaginar" (Portal EBC, 2019) que aborda temas de educação, artes, geografia, direitos da criança, cultura, brincadeiras e comportamento, entre outros. A atração traz reportagens, notas, séries dramáticas e entrevistas e era transmitida pelas rádios Nacional da Amazônia e Nacional de Brasília. O programa pode ser ouvido on demand, no portal da Empresa Brasil de Comunicação (EBC).

Já em âmbito regional, o programa Unespinha, autodenominado "o programa da criança” (Rádio Unesp, 2019), é transmitido, aos domingos, às 9h, pela Rádio Unesp FM, localizada na cidade de Bauru (SP), e pode ser ouvido também, via streaming, no site da emissora. Com proposta jornalística e didático-pedagógica, a atração explora temáticas diversas, do conhecimento científico às questões sociais e de comportamento, num formato que alia entretenimento musical e informação. Diferentemente do Mambembeiro, as edições do Unespinha não estão disponíveis no site da rádio ${ }^{5}$.

A proposta deste artigo é descrever e discutir as características temáticas, de estilo e de estruturação dos dois programas, uma vez que se trata de iniciativas destinadas ao público infantil, as quais, de certa forma, resistem num cenário radiofônico marcado pelo entretenimento mainstream e pelo jornalismo voltado para adultos. Para tanto, busca-se analisar os gêneros e formatos, as estratégias enunciativas

\footnotetext{
${ }^{4}$ Veiculado pelas rádios Nacional e MEC, era transmitido, ao vivo, do auditório da Rádio Nacional, ou de espaços como o SESC, no Rio de Janeiro. Era apresentado pelo cantor, compositor, ator e radialista José Carlos de Souza, o Zé Zuca.

${ }^{5}$ No site, só há informações gerais sobre o programa, sem a publicação das edições que foram ao ar, com exceção de treze arquivos que se encontram disponíveis. cf. www.radio.unesp.br/unespinha.
} 


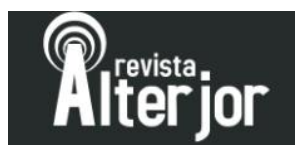

e os recursos estéticos adotados nas atrações, bem como caracterizar as semelhanças e diferenças entre elas.

A partir do estudo, espera-se contribuir para o debate sobre a produção radiofônica segmentada para o público infantil e discutir parâmetros que possam ser aplicados na transformação/criação de programas jornalísticos e/ou educativos de qualidade, voltados para crianças e pré-adolescentes ouvintes de rádio e outras mídias sonoras, como podcast e webradio.

\section{Rádio e criança}

O público infantojuvenil representa uma parcela significativa da população: os brasileiros até 14 anos somam aproximadamente 44 milhões de pessoas, ou 20,28\% do total de cidadãos (IBGE, 2018). Esse enorme contingente de sujeitos é negligenciado na programação radiofônica, o que é preocupante, tendo em vista a importância de produções voltadas para o público de crianças e pré-adolescentes na construção de novas e futuras audiências (Haussen, 1988) e, mais ainda, o fato de que o acesso à comunicação e à informação é um direito de todos.

Também merece destaque o aumento do acesso aos meios digitais e à internet, o que propiciou às rádios a possibilidade de digitalizar seus conteúdos e torná-los acessíveis por computador, tablets, smartphones e players, bem como favoreceu o surgimento de webradios e podcasts (KISCHINHEVSKY, 2009). Essa oferta variada de formatos sonoros vai ao encontro das novas formas de consumo midiático, em relação às quais o segmento infantojuvenil está cada vez mais integrado. Segundo uma pesquisa, realizada em $2014^{6}$, que buscou identificar hábitos e expectativas de brasileiros e seu consumo e uso de mídias, 50\% das crianças de 4 a 6 anos acessam a internet. Abaixo dessa faixa etária, $19 \%$ o fazem com os pais. O uso de aparelhos também é comum desde a mais tenra idade: entre as que têm menos de 4 anos, 67\% mexem no smartphone, $48 \%$ usam computador e $10 \%$, tablets, enquanto $42 \%$ usam o celular para jogar (FERREIRA; MORALES, 2017).

\footnotetext{
${ }^{6}$ Pesquisa Papagaio/Pipa, realizada pela Multifocus Inteligência de Mercado, com 1800 pessoas de 0 a 17 anos, das classes A, B, C, D e E, em 12 capitais brasileiras. Cf. www.multifocus.com.br/papagaio-pipa/.
} 


\section{Aterior}

Esse cenário soa a campainha quanto às possibilidades que se descortinam para a expansão das mídias sonoras. Como ressaltam Diego Weigelt e Veridiana Röhsler (2018, p. 10), com a transformação digital do rádio, talvez este seja o momento e o caminho para fidelizar o público infantojuvenil: "levando em consideração o grande acesso e utilização de tecnologias ligadas à internet, deve-se compreender essa fase de midiamorfose como uma oportunidade para o rádio conquistar mais espaço entre crianças e jovens".

A criança geralmente conhece o meio a partir da família e, na maioria dos casos, o ouve com ela. Rádio, portanto, é 'mídia de adulto' que chega indiretamente até a criança (algum familiar o está ouvindo e ela participa dessa experiência passivamente), mas tal audição vai se tornando cada vez mais autônoma. Essas duas formas de escuta são importantes na formação e consolidação das preferências de consumo radiofônico, nos mais diferentes gêneros (jornalístico, esportivo, de entretenimento etc.). Neste aspecto, é relevante destacar o papel que a programação musical desempenha como atrativo, pois normalmente as crianças buscam o rádio para ouvir música (Ribeiro, 2015).

A partir dessa audição, e também da influência dos amigos e dos outros meios de comunicação, o público infantil forma o seu 'gosto', notadamente influenciado pela música feita para adultos, e não pela música para ou de criança. Todavia, mesmo nos casos em que as canções se destinam especialmente ao público infantil, a criança nem sempre se encontra em 'bons lençóis', haja vista a qualidade de algumas composições. Estudiosos criticam os propósitos de boa parte das 'músicas infantis', dado o conteúdo vazio, a exploração inócua da língua com o fim de entreter superficialmente (diminutivos, rimas fáceis e previsíveis etc.) e a pretensão educadora edificante (Pereira et al., 2010, p. 151-2).

Além da presença de 'música para criança' de baixa qualidade, cabe uma crítica também ao emprego de determinadas fórmulas em boa parte dos programas infantis, como a "mimetização da infância", um cacoete que adquire diferentes facetas: ora é a maneira como os temas são abordados, com superficialidade e simplificação, ora é o estilo empregado pelo/a apresentador/a, que exagera no uso de diminutivos, fala alto e 


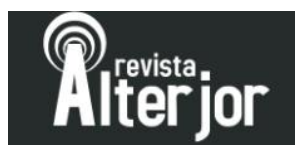

agudo, mantém um clima forçado de alegria e busca encenar um permanente estado de energia e vivacidade. Essa forma de apresentar os assuntos e se dirigir à criança faz supor uma certa dificuldade em perceber com clareza quais seriam os interesses desse coletivo e como atingi-lo:

O universo infantil é frequentemente abordado de modo ingênuo e edulcorado, como se toda criança fosse alegre e feliz por natureza e em tempo integral, como se não vivesse também seus dilemas e conflitos. É uma espécie de infância idílica e inventada pelo adulto que não a viveu, pois ela nunca existiu e talvez nunca existirá. Essa infância é cantada em verso e prosa como um mundo feliz idealizado. Mas quem de nós teve uma infância somente feliz? Outras vezes, as crianças aparecem como seres barulhentos, inquietos e incapazes de ficarem em silêncio, que só sabem correr e fazer bagunça por todos os lados. São sempre ingênuos, pois vivem fazendo perguntas desconcertantes aos adultos, às quais só terão respostas quando atingirem uma suposta maturidade. No entanto, temas considerados sérios ou densos, tais como a perda, a morte, a dor, por exemplo, seriam mais apropriados para adultos (Pereira et al., 2010, p. 152).

Esse 'modo de produção', portanto, parece não saber muito bem qual a melhor maneira de se dirigir à criança, apesar das 'boas intenções'; parece não levar em conta que "a criança exige dos adultos explicações claras e inteligíveis, mas não explicações infantis, e muito menos as que os adultos concebem como tais. A criança aceita perfeitamente coisas sérias, mesmo as mais abstratas e pesadas, desde que sejam honestas e espontâneas" (Benjamin ${ }^{7}$ apud Pereira et al., 2010, p. 152),

Mesmo no caso de programas apresentados por crianças e/ou com a participação delas, não se está imune a uma espécie de 'mimetização reversa': agora é a criança que fala como adulto. Fábio Fernandes, ao analisar um programa educativo em que as crianças integram a equipe de produção, destaca esse problema:

(...) esteticamente o programa faz uso de recursos repetidos por praticamente todas as outras propostas de rádio infantil, exigindo das crianças uma performance em frente ao microfone que é mimetismo, no sentido de repetição, das locuções dos adultos, com o agravante de

\footnotetext{
7 BENJAMIN, Walter. Livros infantis antigos e esquecidos (1924). In: BENJAMIN, Walter. Obras
} escolhidas, vol.1. Magia e técnica, arte e política. São Paulo: Brasiliense, 1985. pp. 235-243. 


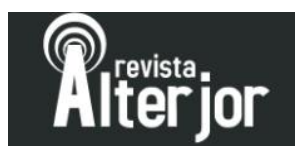

seguirem roteiros de difícil compreensão e dicção. Muitas vezes as crianças pronunciam frases complicadas, desenvolvem (ou repetem) raciocínios elaborados para o texto escrito (Fernandes, 2016, p. 123).

Dessa forma, supera-se uma lacuna, mas se cria outra: a não presença de crianças nas produções é uma crítica que se faz aos programas, pois isso deixa o jornalista/produtor na posição de decidir o que seria de interesse do público infantil (Doretto, 2014, p.41), mas a participação desse público nas atrações não resolve o problema se ela não for genuína. Ou seja, se a atração apresenta textos escritos por adultos para serem lidos por crianças e adolescentes, não há traços do discurso, nem da fala infantis (Cavalcante; Lima, 2006, p. 48).

A despeito desses inconvenientes, o fato é que o rádio, ao se dirigir à criança, serve para entreter, para fazer dançar, para permitir o contato com as coisas do mundo, para ampliar e/ou complementar o conhecimento compartilhado com a escola etc.. Seja a audição involuntária (quando se ouve porque um adulto está ouvindo), seja a autônoma (quando a própria criança seleciona o que quer ouvir), o rádio está inserido na paisagem sonora da vida infantil (Ribeiro, 2015). Ele tem destaque nesse cotidiano e é formador de gostos, como mostram os resultados de uma pesquisa realizada com crianças brasileiras e portuguesas:

\begin{abstract}
Ainda que os relatos dos entrevistados tenham apontado que outras mídias (a TV sem dúvida) são mais importantes que o rádio para sua formação, e que a maioria deles teça uma relação apenas tangencial com o rádio e seus conteúdos, ele é inegavelmente presente; e posso dizer que essa presença, mesmo que não seja percebida como relevante, funcionando mais como pano de fundo, ruído, atua de forma contínua para a constituição de hábitos e padrões de escuta. (Ribeiro, 2015, p. 181)
\end{abstract}

Além disso, os programas de rádio, na sua relação com a criança, podem ser também espaços de sensibilização para a narrativa sonora e os sentidos da sintaxe radiofônica, ou seja, as produções devem ser fator de estímulo para uma "cultura do ouvir": "fica clara, então, a importância pedagógica dos programas infantis, mas não apenas na sua forma clássica de educação. $\mathrm{O}$ rádio também pode garantir à criança $\mathrm{o}$ 


\section{Preiejer}

estímulo à criatividade, à subversão e, principalmente, educar a criança a ouvir" (Fernandes, 2016, p. 113).

\section{Procedimentos metodológicos}

O procedimento adotado na pesquisa foi o estudo de caso, definido por Gil (2002, p. 54) como "uma pesquisa exaustiva, profunda e extensa de uma ou poucas unidades, conhecendo ampla e detalhadamente o objeto".

O corpus de análise foi formado por cinco edições do Mambembeiro e cinco do Unespinha, selecionadas de maneira a contemplar episódios exemplares, que apresentassem a maior variedade de conteúdos e formatos, ainda que os programas tenham características relativamente estáveis. Por isso, a seleção foi aleatória, sem respeitar recortes temporais ${ }^{8}$, e incluiu edições de 2017 a 2019.

Feita a seleção, procedeu-se a audição, decupagem e transcrição completa dos programas, para identificação e compreensão de suas características, conforme os objetivos da pesquisa. Verificou-se inicialmente a articulação dos elementos da linguagem radiofônica (códigos verbal, sonoro e musical) nos programas. Em seguida, buscou-se compreender a composição e a estruturação, identificando formatos, seções, quadros etc. Também se procurou elencar e avaliar as temáticas e sua forma de abordagem. Por fim, realizou-se também o levantamento do estilo da apresentação e os espaços e formas de interação com o ouvinte (sites institucionais, blogs, redes sociais etc.).

\section{Resultados e discussão}

\section{O programa Unespinha}

O Unespinha é uma revista radiofônica ${ }^{9}$ semanal que vai ao ar aos domingos, das 9h às 10h, pela Rádio Unesp (105,7 FM), transmitida em Bauru e região. Ele também pode ser ouvido, via streaming, no mesmo horário, pelo portal da emissora

\footnotetext{
${ }^{8}$ Ressalte-se que, até a conformação do corpus, procedeu-se à audição de dezenas de episódios dos dois programas, de maneira a se obter um panorama de como se constituem as atrações.

${ }^{9} \mathrm{O}$ objetivo principal da rádio revista é fazer o ouvinte experienciar bons momentos e entretê-lo. Trata-se de um formato híbrido, capaz de englobar os mais diversos gêneros e subgêneros, bem como diferentes formatos (Lopez Vigil, 2003).
} 


\section{Rireijor}

(www.radio.unesp.br). O programa se autodescreve como um "formato didáticopedagógico e jornalístico" (RÁDIO UNESP, 2019) e é produzido e apresentado pela jornalista Cilene Barros.

A rádio Unesp FM é uma emissora pública de caráter cultural e educativo, vinculada à Universidade Estadual Paulista (Unesp), e foi fundada em 1991. A sua programação inclui programas musicais, educativos, jornalísticos, esportivos e de divulgação científica.

O Unespinha é uma produção majoritariamente musical, com duração de aproximadamente 60 minutos. A cada edição, aborda-se uma temática em especial, ainda que outras possam ser discutidas superficialmente. Os blocos musicais são intercalados por trechos em texto verbal, durante os quais a temática do dia é discutida na forma de notas, comentários e dicas. Esporadicamente, podem surgir outros formatos, como leitura de textos literários. Trata-se de um programa do gênero especial, que une características de vários gêneros, como educativo, jornalístico e ficcional (Barbosa Filho, 2003)

Basicamente, o programa mantém uma estrutura que se inicia com uma vinheta de abertura, seguida de um pequeno texto em que a apresentadora introduz o tema principal do episódio. Logo após, ela chama a primeira sequência musical e informa os nomes dos intérpretes e das músicas (geralmente uma ou duas). Sempre ao fim dos blocos musicais, a apresentadora faz retomadas e mantém a progressão do programa, ao evocar a atenção do ouvinte com o uso de expressões como "estamos de volta" e o nome Unespinha. Ela retoma o tema do episódio, apresenta uma nota sobre ele (que pode ser um dado estatístico, uma curiosidade, uma informação etc.) e chama a nova sequência musical.

Esse padrão se repete ao longo dos 60 minutos: intercalam-se blocos de música e blocos de texto verbal, sem uma delimitação rígida de duração entre eles. A cada episódio, são apresentadas de 15 a 18 músicas (MPB e canções infantis), que somam aproximadamente 40 minutos do programa, enquanto os textos verbais somam de 10 a 15 minutos. Ao final do programa, a apresentadora dá o crédito das fontes de informação, lista os profissionais envolvidos na produção e agradece a companhia do 


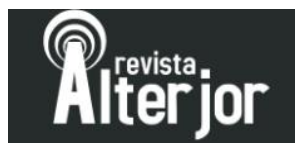

ouvinte. Uma música (não necessariamente a mesma em todas as edições) começa a tocar e marca o encerramento, pois não há vinheta. Às vezes, usa-se o efeito de uma criança dando tchau ou rindo.

Os assuntos tratados no Unespinha são os mais diversos: feiras, quadrinhos, Natal, plantas e flores, férias, hobbies etc. Os assuntos de cada edição relacionam-se geralmente com épocas do ano, datas especiais (comemorativas/religiosas) e eventos que estejam ocorrendo na cidade de Bauru e no mundo, mas também há espaço para temas abstratos, como a morte. Nas edições analisadas, os temas foram violão, doação de sangue, flores e jardins, férias e cuidados no verão.

Toda a apresentação é acompanhada de uma trilha musical em background (BG), a qual geralmente tangencia a temática do episódio. Na edição em que se falou de flores e jardins, por exemplo, a música de fundo foi Primavera, dos compositores Sérgio Cassiano e Silvio Rochael. O uso de efeitos sonoros é raríssimo, assim como o emprego de vinhetas ${ }^{10}$ também é escasso: há somente vinheta de abertura do programa e vinheta de introdução e fechamento de um quadro esporádico chamado "Dica de leitura", o qual apresenta a resenha de um livro infantil, elaborada por um convidado do programa. Assim como este, há outros quadros que também não possuem periodicidade e formato regular, ou seja, não integram a estrutura música/texto verbal (nota) característica da atração e que se repete semanalmente.

Quanto à presença do programa nos meios digitais, só há uma descrição dele no site da Rádio Unesp FM, na aba Programação/Especiais (www.radio.unesp.br/unespinha) e não há perfil em rede social. Em relação à interatividade com o público, as opções são limitadas: somente um e-mail para contato é informado no site e durante a apresentação. Não se faz também qualquer referência à participação do público, como comentário sobre algum e-mail porventura recebido.

Em relação ao estilo de locução empregado nos episódios, o volume da voz é sempre médio, o ritmo é pausado, o timbre é geralmente fechado e o tom ora é grave, ora levemente agudo, o que resulta num efeito de tranquilidade e doçura (Rodero Antón,

\footnotetext{
${ }^{10}$ Segundo Ferraretto (2014), a vinheta serve para separar e identificar partes, mas contém texto verbal, além da música.
} 


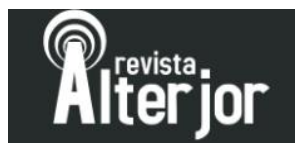

2005). Pode-se dizer que o 'tom' geral da apresentação é suave e acolhedor, mas há momentos em que a performance é 'infantilizada', principalmente com o uso de diminutivos, ou extremamente 'maternal', quando a locução fica pausada e cheia de nuances na entonação. Esses recursos expressivos influenciam diretamente a experiência do ouvinte, dando a impressão de que o Unespinha se dirige a crianças muito pequenas ou que ainda têm pouca capacidade de entendimento das mensagens.

\section{O programa Mambembeiro}

O Mambembeiro se autodenomina "um espetáculo para ouvir e imaginar" (PORTAL EBC, 2019) e aborda temas como lazer e ócio, ciência, arte e direitos da criança, entre outros. A atração traz reportagens, notas e entrevistas e era apresentada pela jornalista Priscila Crispi, na Rádio Nacional da Amazônia (ondas curtas 11780 kHz e $6180 \mathrm{kHz}$ ) e na Rádio Nacional de Brasília (FM 96.1 e AM 980). Ele está fora do ar desde meados de 2018, mas suas edições estão disponíveis no site da Empresa Brasil de Comunicação (EBC) (www.rádios.ebc.com/ mambembeiro). Também no site, podia ser ouvido por streaming, quando ainda era transmitido ${ }^{11 .}$

A estreia, em março de 2017, foi pela rádio Nacional de Brasília, primeira FM do Distrito Federal, inaugurada em 1976. Os principais destaques da emissora são a música popular brasileira, a música instrumental e os programas jornalísticos. Atualmente, ela pode ser sintonizada em todo o DF e entorno, estando disponível também na internet e pelo satélite digital.

O Mambembeiro é uma revista radiofônica de 60 minutos que tem como característica principal simular um picadeiro de circo e o estilo de apresentação circense. Para isso contribuem diversas estratégias, como o programa se apresentar como "circo mambembeiro", o uso do bordão "respeitável público", a música tema, que permanece em BG especialmente na introdução, além de um texto e uma locução

\footnotetext{
${ }^{11}$ A página do programa, no site da EBC, disponibiliza edições completas e recortes do programa e ainda informa os horários de transmissão (sábados e domingos), a atração não consta das grades de programação de nenhuma emissora da rede, disponibilizadas na plataforma.
} 


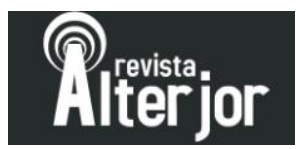

ritmados, rimados e cheios de trocadilhos. A vinheta de abertura do programa, por exemplo, traz uma voz masculina, que anuncia:

Respeitável público, senhoras e senhores, meninas e meninos, criancinhas e crioncinhos. Você ligado de Norte a Sul deste imenso Brasil, pode aumentar o volume do rádio. Sintonize aí, que o circo tá chegando. Que rufem os tambores! Soem os clarins! A rádio nacional orgulhosamente apresenta...

Assim como sua inspiração, o Rádio Maluca, o Mambembeiro também busca simular ambientes e imagens. O primeiro era transmitido, ao vivo, de um teatro, tentando passar pelo rádio o que acontecia na materialidade do palco (daí seu slogan "ver o programa pelos buraquinhos do rádio"). O Mambembeiro, por sua vez, tenta recriar a 'materialidade' do circo, sem nela estar concretamente. Para isso, ancora-se no texto verbal, na trilha sonora e na linguagem circense.

Assim como o Unespinha, o Mambembeiro também pertence ao gênero especial, integrando características de vários gêneros, como jornalístico, ficcional, musical e educativo. O programa é constituído de música, notas, entrevista e formatos especiais esporádicos, como série ficcional ${ }^{12}$. Cada edição apresenta um tema em destaque, o qual pode ser definido por época do ano ou assuntos em alta no momento, como Ano Novo, literatura, política e imigração etc..

O programa mantém uma vinheta de abertura, seguida de um pequeno texto verbal introdutório sobre a temática que será tratada no dia. Essa abertura geralmente é feita de uma maneira lúdica e com rimas. O estilo coloquial, com uso de neologismos, gírias e termos afetivos, também perpassa toda a atração, como se pode ver nos trechos a seguir:

Bom dia, boa tarde, boa noite, não importa a hora. O Mambembeiro já chegou para adoçar a vida. Venham todos e esqueçam a lida, por uma hora é permitida todo o tipo de fantasia esquecida. Esse nosso espetáculo, hoje, está espetacular

\footnotetext{
${ }^{12}$ Na radiossérie "Circus Mambembe", os personagens Menina Leca e Palhaço Baldinho viajam no tempo para acompanhar o desenvolvimento do circo, desde a Roma Antiga até os tempos atuais. Cada episódio possui, aproximadamente, 20 minutos. Trata-se da primeira experiência do programa com o formato radiossérie e teve a duração de cinco episódios (PORTAL EBC, 2019).
} 
Olá, ouvinte e ouvinta, seja muito bem-vindo e muito bem-vinda. Tá no ar o meu, o seu, o nosso Mambembeiro! pra quem já está nos acompanhando o ano inteiro, chegue aqui que gente quer te dar um cheiro!

(...) E se você é fã, brother, parça com certeza não está perdendo nem um episódio sequer da nossa série fora de série que conta a história do circo: Circus Mambembe!

Logo após a abertura do programa, pelo menos duas músicas dividem os tópicos. Assim como o Unespinha, o Mambembeiro também não possui uma quantidade de blocos determinada, mas o mais comum é de seis a oito, por edição. A programação musical é predominantemente brasileira, podendo ir da MPB ao rap nacional. Logo após a abertura e as músicas iniciais, entra o quadro "Repórter Mambembeiro", em que um especialista fala sobre o tema da edição. Nos episódios analisados, os entrevistados foram, por exemplo, um pedagogo (artistas), um escritor e ilustrador (ilustração e literatura na infância), um físico (Ano Novo), a coordenadora de uma fundação de apoio a pessoas com deficiência visual (acessibilidade) e um historiador (imigração). As entrevistas do "Repórter Mambembeiro" podem durar de 10 a 20 minutos. Após o quadro, há mais um intervalo musical.

O produto apresenta uma estrutura semifixa, ou seja, alguns quadros ou segmentos são recorrentes, mas praticamente todas as edições apresentam variações: ora a sequência de conteúdos é alternada, ora quadros são introduzidos. A exceção é o "Repórter Mambembeiro", que integra todas as edições. Dentre os quadros recorrentes está o "Eu falo criancês", em que uma criança dá sua opinião sobre o assunto tratado (na edição sobre Ano Novo, por exemplo, o participante expôs o que esperar para o novo ano que se inicia). Há também o quadro "Laboratório Mambembeiro", em que uma outra apresentadora da emissora interpreta a personagem Cientista Tita, que responde uma dúvida do ouvinte, enviada por carta. O estilo adotado no quadro é bastante didático, pois a personagem explica o assunto para a criança de forma simples e clara, sem a utilização de termos técnicos e com abundância de efeitos sonoros. Outra seção recorrente é o "Canto que eu conto", em que um escritor é convidado a narrar um texto de sua autoria. A narração é dramatizada, com o emprego de efeitos sonoros, o que garante a ambientação da trama apresentada, de maneira dinâmica e criativa. 


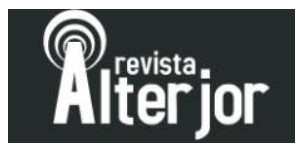

Cada quadro tem uma vinheta própria, composta por uma melodia e a voz da apresentadora Priscila falando o nome do segmento. Nos blocos musicais, a mudança de canção é marcada por uma vinheta (que funciona como uma espécie de cortina ${ }^{13}$ ) que tem um formato inusitado: a voz de uma criança tentando pronunciar corretamente o nome do programa.

O estilo da apresentação é sempre exageradamente 'pra cima': o tom é aberto, o timbre é agudo e o ritmo é acelerado, o que imprime energia, alegria e euforia ao sentido do texto (Rodero Antón, 2005). Ainda se que consiga, com esse recurso, manter o dinamismo da atração, tal estilo soa forçado e excessivo em boa parte do programa. Há momentos também em que se recorre muito ao uso de diminutivos e expressões típicas do universo da criança. Tais traços são característicos da mimetização da infância tão comuns nos programas infantis, a qual já foi discutida acima e também afeta o Mambembeiro em alguns momentos.

Diferentemente do Unespinha, o Mambembeiro divulga formas de o ouvinte entrar em contato com a produção do programa, além do e-mail oficial da emissora: whatsapp, caixa postal, endereço e CEP da Rádio Nacional. Por esses meios, o ouvinte pode participar por correio eletrônico, mensagem de áudio e carta. O programa não mantém perfil em rede social.

\section{Exploração de formatos e sensibilização para a escuta}

Unespinha e Mambembeiro têm alguns traços comuns: são transmitidos pelo meio rádio e se encontram disponíveis também na internet, para consumo em streaming e on demand, respectivamente; são produções de emissoras públicas que, talvez por não terem compromissos comerciais, podem desenvolver propostas voltadas ao público infantil; são projetos de cunho educativo-cultural e informativo; o estilo de apresentação mimetiza a infância e/ou mantém o tom artificial de alegria e energia, como já discutido

\footnotetext{
${ }^{13}$ Cortina é um trecho musical que identifica ou separa parte do programa em relação ao todo (Ferraretto, 2014)
} 


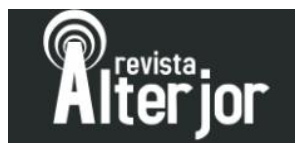

acima. Apesar disso, é possível observar importantes diferenças temáticas, estilísticas e de composição entre as duas iniciativas.

O Mambembeiro, por exemplo, explora assuntos que normalmente ocupam as discussões do universo adulto, como a valorização da classe artística, o fenômeno das imigrações e o assédio sexual. Apresenta também formatos diferenciados, como dramatização (quadro "Canto que eu conto" e radiossérie "Circus Mambembe"), que estimula a imaginação das crianças, com exploração criativa da sintaxe radiofônica. $O$ Unespinha, por sua vez, prende-se mais a temas de caráter educativo, como curiosidades científicas, língua e literatura, hábitos de higiene, reino animal e natureza, geralmente abordados de maneira bastante didática.

Nota-se que as duas atrações, apesar de se autodeclararem programas jornalísticos/informativos, exploram parcialmente o gênero ${ }^{14}$ e os formatos jornalísticos ${ }^{15}$ no texto, fazendo uso basicamente de notas e entrevistas. Isso é mais nítido no caso do Unespinha, que apresenta principalmente notas. Além disso, o Unespinha também corrobora a avaliação de estudiosos de que a maioria dos programas voltados ao público infantil oferece poucos estímulos à imaginação do ouvinte (Pereira et al., 2010), devido à ancoragem no texto verbal, ao escasso emprego dos efeitos sonoros e à sonoplastia pouco criativa e diversificada.

A exploração de uma sintaxe radiofônica criativa e diversificada é requisito fundamental para a sedução, a sensibilização e o despertar da atenção da criança. Por isso, o ‘abandono do sonoro', ou seja, a excessiva tentativa de construção de imagens e visualizações do mundo, com pouca exploração e experimentação das totalidades do som, é uma característica que, infelizmente, ainda dá o contorno de muitas produções radiofônicas para o público infantil. É a "subtração" do potencial expressivo do rádio (sobre o qual tanto alertava Rudolf Arnheim), em nome de uma prevalência do 'visual'.

\footnotetext{
14 Segundo BARBOSA FILHO (2003), os gêneros radiofônicos são classificados em jornalístico, educativo-cultural, de entretenimento, publicitário, propagandístico, de serviço e especial. O gênero jornalístico possui um vínculo com a realidade e com os acontecimentos concretos (LOPEZ VIGIL, 2003).

15 Os formatos jornalísticos são nota, notícia, boletim, reportagem, entrevista, comentário, editorial, crônica, radiojornal, documentário jornalístico, mesa-redonda, programa policial, programa esportivo e divulgação técnico-científica (BARBOSA FILHO, 2003).
} 
Não está provado empiricamente que o rádio é mais ou menos libertador que a TV no estímulo à criatividade das crianças, mas é fato que a linguagem radiofônica em uso carrega uma necessidade intrínseca de visualização, como uma espécie de concorrência com a estética da televisão. Seja pelas câmeras instaladas nos estúdios divulgando imagens pela internet, seja por fazer a criança "ver o programa pelo rádio", a hiper-exposição imagética à qual somos sujeitos diariamente influencia diretamente nas elaborações dos programas de rádio. Desde os locutores esportivos que nos estimulam a reconstruir a imagem do campo de futebol às reportagens das emissoras all news que nos apresentam notícias em forma de verbalizações, abstraindo as sonoridades. Portanto, ao se falar em visibilidade, não se trata necessariamente de uma ideia da imagem pictórica no rádio, mas da subtração do sonoro em prol da construção narrativa verbal e informativa, mais eficiente e econômica. (Fernandes, 2016, p. 123)

Entre o público infantil, o rádio é acompanhamento, "ruído de fundo", e geralmente adquire audição atenta quando a música preferida do ouvinte toca. Se a proposta é de exploração de outros formatos que não o mero entretenimento musical, tão importante quanto os conteúdos são as estratégias de sensibilização para a escuta, o que exige criatividade dos produtores de programas como o Unespinha e o Mambembeiro para atingir o intento de sensibilizar a criança para o consumo de mensagens radiofônicas.

\section{Considerações finais}

O público infantil não é devidamente atendido pelo rádio, apesar de este ser considerado um meio dinâmico, capaz de atingir múltiplas audiências. Ainda assim, há iniciativas que buscam suprir essa lacuna, como os programas Unespinha e Mambembeiro.

Sem entrar no mérito da qualidade dos programas, é forçoso reconhecer que eles, em maior ou menor medida, repetem e reforçam os 'vícios' e equívocos de muitas produções do gênero. A despeito desses problemas, os programas realizam seu propósito de levar informação, cultura, conhecimento e entretenimento para um público geralmente alijado da produção radiofônica no país. Dessa maneira, proporcionam à 


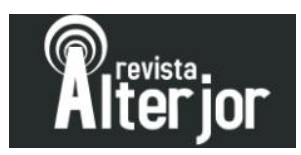

criança outras possibilidades de consumo autônomo e especializado de conteúdos, para além daquilo que ela já acessa 'por tabela', quando ouve rádio porque um adulto está ouvindo:

O rádio, portanto, pode ser uma importante ferramenta no processo de aprendizagem, já que as crianças também consomem muitas mídias e, mesmo que não se ofereça a elas um conteúdo exclusivo, podem ser influenciadas por aquilo que é feito para outros públicos. Ao ouvir no rádio, por exemplo, o conteúdo que os pais consomem, pode ter capacidade de se informar e tirar conclusões. Lacunas podem ser deixadas nesse processo e, por isso, torna-se importante pensar também na possibilidade de oferecer à criança material específico, compreensível e que possa ser acessado facilmente, ampliando assim, sua participação na sociedade (Weilgelt; Röhsler, 2018, p. 12)

Despertar o interesse da criança, graças à qualidade da produção, favorece a formação de novos públicos, os quais podem ser ainda mais ampliados se a oferta se estender aos ouvintes já inseridos no consumo digital. Nesse sentido, os dois programas apresentam esse potencial, uma vez que também estão disponíveis na internet. Considerando que o público-alvo das duas iniciativas é formado por nativos digitais (Doretto, 2010, p. 2), seria interessante que os programas explorassem mais esses meios. Afinal, a internet pode beneficiar o rádio, ao suprimir os limites de alcance da transmissão e permitir o acesso à programação por streaming ou sob demanda, com a utilização de dispositivos como smartphones, tablets e computadores pessoais.

A análise de como as duas atrações se configuram mostrou que elas se inserem no gênero especial e apenas tangenciam o jornalístico, uma vez que exploram também o literário, o dramatúrgico e o musical. O Unespinha é o que menos apresenta variedade de formatos, inclusive os jornalísticos, balizando sua proposta na intercalação de música e notas informativas. Já o Mambembeiro oferece um leque mais ampliado de produtos, com entrevistas, reportagens, radiosséries etc.

Mesmo que o jornalismo não seja o 'carro-chefe' das atrações, apesar da descrição que elas fazem de si mesmas, é importante ressaltar a importância dos programas no consumo de informação entre o público infantil. O próximo passo talvez possa ser ampliar a participação da própria criança nessa produção informativa, respeitando características fundamentais como "as áreas sobre as quais as crianças 


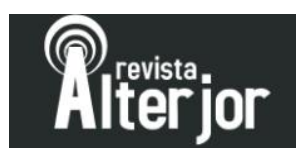

podem se informar, do que podem falar e o que podem ler e ouvir, como podem se divertir, como o produto feito para elas deve ser apresentado, de que material deve ser confeccionado" (Doretto, 2014, p. 61).

Os programas infantis geralmente têm proposta de complementação pedagógica, a qual está por trás de boa parte das mensagens apresentadas, não importa o formato que adquiram: contação de histórias, reportagens, dramatizações etc. Nesse sentido, Unespinha e Mambembeiro, cada um a seu modo e com estilo próprio, buscam entreter, mas também tornar o rádio um espaço de ampliação de conhecimentos e cultura. Nesse esforço, porém, falta um pouco mais de arrojo na produção de vinhetas e textos (principalmente no caso do Unespinha), maior participação da criança na produção e uma abordagem mais espontânea e menos mimetizada. Além disso, a programação destinada à criança deve envolvê-la com carinho e cuidado, seja por meio das temáticas abordadas, seja pela maneira como as mensagens são comunicadas. Afinal,

Antes de pertencer a uma faixa etária, as crianças são seres humanos. A infância é uma fase da vida em que não apenas se assimilam informações e conteúdos, mas em que se aprendem hábitos e valores que podem ser levados por toda a vida. (...) É durante a infância que os sujeitos mais desenvolvem suas habilidades básicas cognitivas e motoras necessárias à vida. É nesse período também que estruturamos a linguagem e compreendemos as "regras" que permitem a vida em comum. Por isso é tão importante o acesso à cultura, à educação e à saúde de qualidade, sobretudo nos primeiros anos. A formação que se tem na infância tem impactos diretos no futuro jovem/adulto. (Pereira et al., 2010, p. 151)

Por isso, uma programação rica e instigante não se deve limitar a ensinar conteúdos, muito menos se limitar a reproduzir os típicos conteúdos do 'mundo adulto', pois, mesmo tendo a criança total capacidade de entender, à sua maneira, a realidade que a cerca, ela vivencia momentos diferentes da existência, e os produtores de programas não devem negligenciar o formato que as mensagens adquirem. Ainda que seja possível trabalhar conteúdos que frequentam a programação geral, é aconselhável que isso seja feito com inventividade e se aproximando o máximo possível do universo de discurso da criança, de maneira a despertar sua curiosidade e interesse pelos assuntos, respeitar sua inteligência e estimular sua sensibilidade. 


\section{Referências}

BARBOSA FILHO, André. Gêneros Radiofônicos. São Paulo: Paulinas, 2003.

CAVALCANTE, Andréa P. P.; LIMA, Nonato. "Criança e adolescente no rádio: múltiplas vozes tecendo cidadania?" In: SAMPAIO, Inês S. V.; CAVALCANTE, Andréa P. P.; ALCÂNTARA, Alessandra Carlos. Mídia de chocolate: estudos sobre a relação infância, adolescência e comunicação. Rio de Janeiro: E-papers, 2006. p. 47-62.

DORETTO, Juliana. "Jornalismo infantil e os nativos digitais". In: INTERPROGRAMAS DE MESTRADO DA FACULDADE CÁSPER LÍBERO, 6, 2010, São Paulo. Anais... São Paulo: Faculdade Cásper Líbero, 2010.

DORETTO, Juliana. "Jornalismo para a infância: uma proposta de definição". $C$ Legenda - Revista do Programa de Pós-graduação em Cinema e Audiovisual, [S.1.], n. 30, p. 59-72, ago. 2014.

FERNANDES, Rodrigo Fonseca. "Brincando com os sons: os programas infantis de rádio como experiência da cultura do ouvir". Revista Rádio-Leituras, Mariana-MG, v. 07, n. 01, p. 108-125, jan./jun. 2016.

FERRARETTO, Luiz Artur. "Possibilidades de convergência tecnológica: pistas para a compreensão do rádio e das formas do seu uso no século 21". In: CONGRESSO BRASILEIRO DE CIÊNCIAS DA COMUNICAÇÃO, 30, 2007, Santos. Anais... São Paulo: Intercom, 2007.

FERRARETTO, Luiz Artur. Rádio: teoria e prática. São Paulo: Summus Editorial. 2014.

FERREIRA, Thais; MORALES, Carolina. "Mediações familiares no uso de mídias digitais por crianças de 0 a 5 anos". In: SEMINÁRIO DE INICIAÇÃO CIENTÍFICA E TECNOLÓGICA DA PUC-RIO, 25, 2017, Rio de Janeiro. Anais... Rio de Janeiro, PUC, 2017.

GIL, Antonio C. Como elaborar projetos de pesquisa. 4 ed. São Paulo, Atlas, 2002.

HAUSSEN, Doris Fagundes. Rádio e criança: um estudo sobre a ausência de programação infantil nas emissoras de Porto Alegre. 1988. 207f. Dissertação (Mestrado em Comunicação). ECA/USP, São Paulo, 1988.

HERSCHMANN, Micael; KISCHINHEVSKY, Marcelo. "A 'geração podcasting' e os novos usos do rádio na sociedade do espetáculo e do entretenimento". Revista FAMECOS, Porto Alegre, v. 15, n. 37, p. 101-106, dez. 2008.

IBGE Instituto Brasileiro de Geografia e Estatística. Projeções e estimativas da população do Brasil e das Unidades da Federação - revisão 2018, 2. ed. Rio de Janeiro: IBGE, 2018. Disponível em <https://www.ibge.gov.br/apps/populacao/projecao//> Acesso em 21 mai 2020.

KISCHINHEVSKY, Marcelo. "Cultura da portabilidade - novos usos do rádio e sociabilidades em mídia sonora". Observatório (OBS*), Lisboa, v.3, n.1, p. 223-238, 2009. 


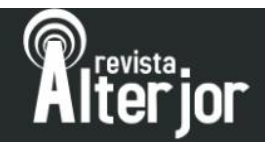

LOPEZ VIGIL, José Ignacio. Manual urgente para radialistas apaixonados. São Paulo: Paulinas, 2003.

PEREIRA, Eugênio Tadeu et al. "Música e infância no rádio: o programa Serelepe na Rádio UFMG - Educativa”. Per musi, Belo Horizonte, n. 22, p. 150-156, dez. 2010.

PORTAL EBC. [Site da emissora]. Disponível em <http://radios.ebc.com.br/mambembeiro> Acesso em 09 jul 2019.

RÁDIO UNESP. [Site da emissora]. Disponível em <http://www.radio.unesp.br/unespinha>. Acesso em 07 mai 2019.

RIBEIRO, Adriana Gomes. A criança em situação de escuta: uma aproximação à audiência infantil de rádio. 2015. 226f. Tese (doutorado em Educação). Pontifícia Universidade Católica do Rio de Janeiro, Rio de Janeiro, 2015.

RIBEIRO, Adriana. “Criança ainda ouve rádio?”. Revista Pontocom, 19 out. 2016. Disponível em <http://revistapontocom.org.br/artigos/crianca-ainda-ouve-radio>. Acesso em 22 de jan 2020.

RODERO ANTÓN, Emma. Producción radiofónica. Madrid: Cátedra, 2005.

WEIGELT, Diego; RÖHSLER, Veridiana.“'Dá para ouvir no celular? Eu não sei!' - O rádio e as crianças em Venâncio Aires-RS". Revista Rádio-Leituras, Mariana-MG, v. 09, n. 02, p. 09-28, jul./dez. 2018. 